\title{
Velocity and direction of plate displacements by latitude observations
}

\author{
E. PROYERBio - V. QUeSAda (*)
}

Received on January sth, 1973

\begin{abstract}
Riassuxto. - Con riferimento ad un precelente lavorn ( $\left.{ }^{8}\right)$ con il quale sono state dedotie le velocita di seorimento dei bloceli AmericaAurasia ex America-Parifieo, secondo la ricostruzione di Je Pichon, utilizanndo la lunga serie (70 anni) di osservazioni di latitudline delle Stazioni ‘el SIJ, gli autori preudiono in esame il problema dell'eflet to che la indeterminazione sulla conosenza delle coortinate tei poli di rotazione kej blocehi, letermina sul calcolo della velocità di scorrimento.

Farendo ricorso ad un procedimento di ottimizzazione dei dati vengons keterminate poi le velocita di scorrimento e le eoordinate del polo di rotazione dei blocehi America-Eurasia. I risultati si accordano con quelli in precedenza sleterminati $\left(^{6}\right)$ e risultano nello stesso ordine di gramulezza di quelli tlertotti da rilevanenti geologiei e treofisici.
\end{abstract}

Summars, -. The results oblained by the authors in a forecoing puper $\left(^{6}\right)$, providing completely independent evidence on the plate tectonic's hypothesis, ares siscussect. Ifow rritical is the ehoice of the rotational pole position of the plates is earefully analysecl.

The location of the centre of rotation and the rate of rotation of Ameriea-Eurasia plate has been successively olutained $1, y$ the last-square fit method. These results are in good agreement with geophysical and geologrical measmements and ronfirm the possibility of using astronomical data in the stukly of plate tectonies.

\section{INTRODUCHION}

Using Le Pichon's ( $\left.{ }^{2}\right)$ reconstruction, the $A . A .\left(^{6}\right)$ computed the rotation rate of the Eurasian-American and Pacific-American

(*) International Iatitude Station, Cagliari. 
plates from astronomical latitudes observed in the five international astronomical stations of Hizusawa (Japan), Kitab (USSR), Carloforte (Italy), Gatithersburg and Ukiah (USA) situated on the + 39" $\mathrm{S}^{\prime}$ parallel. The data analysed cover a period of 70 years. From this analysis it results that in general, disregarding local distorsions which undoubtedly oceur, the Kitab and Carloforte stations can be considered as lying on the Eurasian plate. Mizusawa also lies on this plate, although close to the boundary. The fourtl and fiftl stations, Gaitlersburg and Ukiah, must be on clifierent plates. Gaithorsburg lies near the center of the American plate and Ukial must be considered as moving with the East Pacific plate. This plate is almost entirely consumed by the American plate and only a small part remains, whose motion is essentially north-west.

To determine the value of the rotation rate $\omega_{k}$ of diflerent plates (b) by the secular variations of the latitude $b_{t}$ of the station (i) as well as the secular motion of the Eartly's pole ( $n)$, condition equations of the type

$$
b_{(j)}=u \cos \left(\lambda_{s}-v\right)-\omega_{k} \cos \Phi_{k} \sin \left(L_{k}-\lambda_{1}\right)
$$

were used, in which the first term of the second member represents the eflect of secular polar motion on observel latitude variations, while the second term represents the effect of the rotation of the station $(j)$ of longitude $\lambda_{3}$ around the rotation pole $(k)$ of coordinates $I_{k}$ and $\Phi_{k}$.

The resulting absolute rates of the dificrent plates, averaged on the busis of various cases treated (6) are found to be

$$
\begin{array}{ll}
-0^{\prime \prime} .0027 / \text { year } & \text { (Eurasian plate) } \\
\pm 0^{\prime \prime} .0002 & \\
+0^{\prime \prime} .0015 / \text { year } & \text { (Ameriean plate) } \\
\pm 0^{\prime \prime} .0002 & \\
+0^{\prime \prime} .0018 / \text { year } & \text { (NE Pacific plate) } \\
\pm 0^{\prime \prime} .0002 &
\end{array}
$$

These results are in excellent agreement with the plate tectonics theory and show that long-term variations in the motion of the stations can be found by careful analysis of very long series of astronomical lata. 
INTERNAL AND EXTTRNAL ERRORS BY DETERMINING POLE AND ANGLLAR JRATES

The polar coordinates $\Phi_{k}$ and $L_{k}$, which are obtained by determining the relative motions of different plates, are generally affected by observation errors which have repercussions on the determination of the absolute rates calenlated by means of relation [1].

The polar coomlinates of ilfferent plates are usually established directly from sprealing rates and fracture zone azimuths (azimuths of the transform faults). In particular, the positions of the center of rotation adopted by Le Piehon (2) are obtained from the azimuths of the fracture zones. Tle standard sleviations of measured from computeil azimuths given by Le Pichon $\left({ }^{2}\right)$ are +-50.7 for the AmericanPacific pole and $\$ 90.1$ for the American-Eurasian pole. These quantities only indirectly give an idea of the imprecision with which rotation pole coordinates are determined. Becanse of the procedure of ahlculating the cooribinates of the pole used by Le Pichon (2), the accuracy of these coordinates an be computed only "a posteriori".

From the spherical triangle (Fig. 1) having as vertices the geographical north pole $F_{n}$, the rotation pole $P_{k}$ of the plate $(k)$ on which

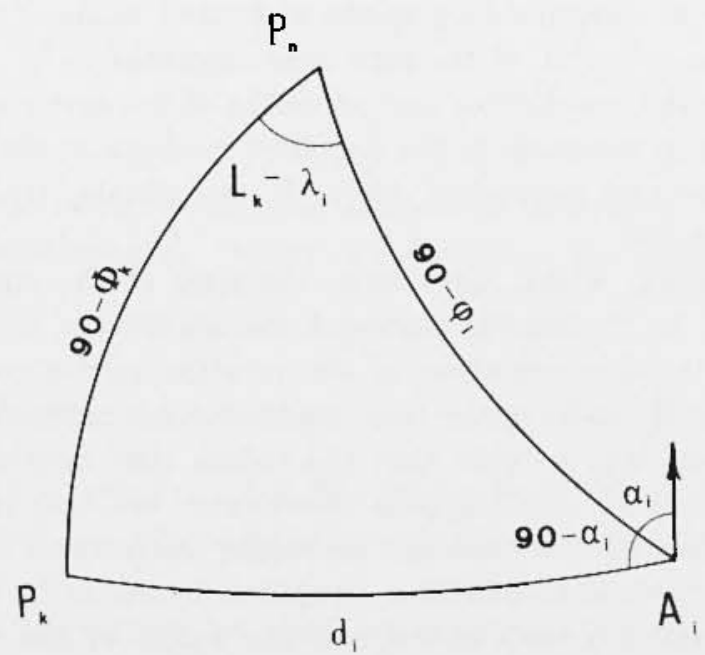

Fig. 1. - Spherieal triangle $P_{n} P_{k} A_{l}$. The points $P_{n}$ and $P_{k}$ correspond to the north greographical pole and the rotation pole of the plate. 
the point $A_{\imath}$, at which the azimutlis $a_{i}$ of the fracture zone were taken, lies, and the point $A_{i}$ itself, we chn write the following spherical relations:

$\sin \Phi_{k}-\ldots \sin \phi_{i} \cos d_{i}+\cos \varphi_{i} \sin d_{i} \sin \alpha_{i}$

$\cos \phi_{k} \cos \left(L_{k}-\lambda_{i}\right)=\cos \varphi_{i} \sin d_{i}-\sin \varphi_{i} \cos d_{i} \sin \alpha_{i}$

$\cos \phi_{k} \sin \left(L_{k}-\lambda_{i}\right)=\sin d_{i} \cos \alpha_{i}$

in which $d_{(t)}$ is the angular distance $P_{k} A_{t}$, while $\varphi_{(i)}$ and $\lambda_{(i)}$ are the geographic coordinates of point $A_{i}$.

From these, we can easily obtain

$$
\operatorname{tag} \Phi_{k}-\cos \left(L_{k}-\lambda_{i}\right)=\sec \varphi_{i} \sin \left(L_{k}-\lambda_{i}\right) \operatorname{tag} \alpha_{i}
$$

from which, in developing and neglesting the second order term, we lave

$$
\begin{gathered}
\cos \varphi_{i} \operatorname{cosec}\left(L_{k}-\lambda_{i}\right)\left(1+\operatorname{tag}^{2} \phi_{k}\right) \Delta \Phi+ \\
\left\{\cos \varphi_{i}-\cot \left(L_{k}-\lambda_{i}\right) \operatorname{tag} \alpha_{i}\right\} \Delta L=\left(\mathrm{L}+\operatorname{tag}^{2} \alpha_{i}\right) \Delta \alpha_{i}
\end{gathered}
$$

By means of this relation it is possible to calculate the theoretionl values of the uncertainties $\Delta \Phi$ and $\Delta L$ of the coordinates of the rotation center $P$ corresponding to the absoluted value of the standard deviations $\Delta \alpha_{i}= \pm 9^{\circ} .1$ of fracture zone azimuths.

Utilizing the coordinates and azimuths of fracture zones $A_{i}$ given by Le Pichon ( $\left.{ }^{2}\right)$ referring to the center of rotation of the American Eurasian plate and supposing $\Delta \phi=\Delta L$, we obtain, by formulu [2], $|\Delta \Phi|=|\Delta L| \simeq 20^{\circ}$.

These values, which agree with the sizes of the ellipse of error computed by Le Pichon (2), represent the amount of accuracy to be expected in the determination of the rotalion center coordinates of the Amerien-Eurasian plate from fracture zone azimuths.

It is interesting to note that the values thus determined of the indeterminations of rotation pole coordinates are also in agreement with the values of the external precisions determined on the basis of center of rotation coordinates computed by diflerent authors.

In the first four lines of Table 1 , the values of the rotation pole coordinates and the relative rate of rotation of the American-Eurasian plate determined by different authors are given. 
The standard deviations of the coordinates observed from the average given in Table 1 are:

$$
\begin{aligned}
& \sigma_{\Phi}= \pm 11^{\circ} \\
& \sigma_{L}= \pm 19^{\circ}
\end{aligned}
$$

\begin{tabular}{|c|c|c|c|}
\hline$\Phi$ & $I$ & $10^{-7} \mathrm{deg} / \mathrm{yr}$ & Authors \\
\hline $\begin{array}{l}78^{\circ} \mathrm{N} \\
63^{\circ} \mathrm{N} \\
60^{\circ} \mathrm{N} \\
48^{\circ} \mathrm{N} \\
8 \overline{0}^{\circ} \mathrm{N}\end{array}$ & $\begin{array}{l}102 \circ \mathrm{E} \\
137^{\circ} \mathrm{F} \\
135^{\circ} \mathrm{E} \\
155^{\circ} \mathrm{F} \\
57^{\circ} \mathrm{W}\end{array}$ & $\begin{array}{l}2.8 \\
2.1 \\
2.4\end{array}$ & $\begin{array}{l}\text { Le Pichon }\left({ }^{2}\right) \\
\text { Le Piehon }\left({ }^{4}\right) \\
\text { Morgan }\left(^{5}\right) \\
\text { Chase }\left({ }^{1}\right) \\
\text { Proverbio \& Quesada }\left(^{6}\right)\end{array}$ \\
\hline
\end{tabular}

Table 1 - Relative Vhetor of Marerica-Eukasian Prate Rotatron

From relation [1], negleeting the effect of secular polar motion $u$ on secular latitude variations, for the angular rate of the stations lying on the American-Jurasian plate we find

$$
\omega_{k}=-\frac{\left[b_{j} a_{j}\right]}{\left[u_{j} a_{j}\right]} \quad(i j-1,2,3,4)
$$

where

$$
a_{j}=\cos \Phi_{k} \sin \left(X_{k}-\lambda_{j}\right)
$$

and $j=1,2,3,4$ refers to the fonu stations of Mizusewa, Kitab, Carloforte and Gaithersburg. From the foregoing we immediately find

$$
\left[a_{j}^{2}\right]^{2} \Delta \omega_{k}=A\left[a_{j}^{2}\right]+B\left[a_{j} b_{j}\right]
$$

where the coefficients $A$ and $B$ are

$$
\begin{aligned}
& \Lambda=\left[b_{j} \sin \Phi_{k} \sin \left(L_{k}-\lambda_{\jmath}\right)\right] \Delta \Phi_{k}-\left[\cos \Phi_{k} \cos \left(L_{k}-\lambda_{j}\right)\right] \Delta X_{j} \\
& B=\left[\sin 2 \Phi_{k} \sin =\left[L_{k}-\lambda_{\jmath}\right)\right] \Delta \Phi_{k}-\left[\sin 2\left(L_{k}-\lambda_{j}\right) \cos ^{2} \Phi_{k}\right] \Delta I_{k}
\end{aligned}
$$

Utilizing the values for secular variations $\left.b,{ }^{6}\right)$ and considering the rotation center coordinates $\left({ }^{2}\right)$ we find

$$
\Delta \omega=-0,30 \Delta \Phi_{k}+0,42 \Delta L_{k} \quad\left(10^{-3} \mathrm{sec} \text { of arc/yr }\right)
$$


Although the reliability of this solntion is rather searse (sinec the computed weight of the quantity $\Delta \omega$ is only 0.006 ) in any case we have, keeping in mind tle maximum uncertainties in calculating the coorlinates $\Phi_{k}$ and $L_{k}$ (order of $10^{\circ}$ ), an uncertainty in the computed angular rate of the same magnitude of the angular rate by the A. A. (i) determined.

$A$ s the rhoice of pole position in rotation calculation by means of the equation [1] seems to be rather critical, we considered it opportune to reconsider the whole problem by turning to a difierent criterion of data processing.

DETERMIXATION OF ROTATION CENTER AND RATE FROM ASTRONOMICAL IATITLDES

The location of the center of rotation and the rate of rotation of the American-Enrasian plate was determined by the least-square fit method, similar to the one used by Ie Pichon for the determination of rotation parameters of rigid blocks.

Tle numerical method of fitting minimizes the sum of the squares or the standard deviations of the residuals

$$
\Delta \varphi_{i}=\left(b_{\mathrm{obs}}-b_{\mathrm{cal}}\right)_{t} \quad(i=1,2,3,4)
$$

between the observed values of secular latitude variations and those alculated by the expression [1]. To calculate this expression, the fixed parameters $n=0^{\prime \prime} .0030$ and $v=69^{\circ} .6$, determined by the $\Lambda . \Lambda .\left(^{\circ}\right)$ with sufficient accuracy, which characterize the secular motion of the Earth pole, were introduced.

The values of $b_{\mathrm{eal}}$ were therefore calculuted by meturs of [1] as a function of the parameter $\omega_{k}$, changing the coorinates $\Phi_{k}$ and $L_{k}$ by steps of five degrees over the range

$$
\begin{aligned}
& 0 \leqslant \Phi_{m} \leqslant 85^{\circ} \\
& 0 \leqslant L_{n} \leqslant 355^{\circ}
\end{aligned}
$$

The values of the standarid deviation

$$
\sigma_{k, m, n}\left(\omega_{k}, \Phi_{m}, L_{n}\right)=\left[\Delta \varphi_{i}^{2}\right]_{m, n}^{1_{/ 2}} \quad(i=1,2,3,4)
$$

are plotted in different diagrams. $A$ s an example, in Fig. 2 we represent the values of $\sigma_{k, m, n}$, corresponding to $\omega_{k}= \pm 0^{n} .0012$, with the plus 


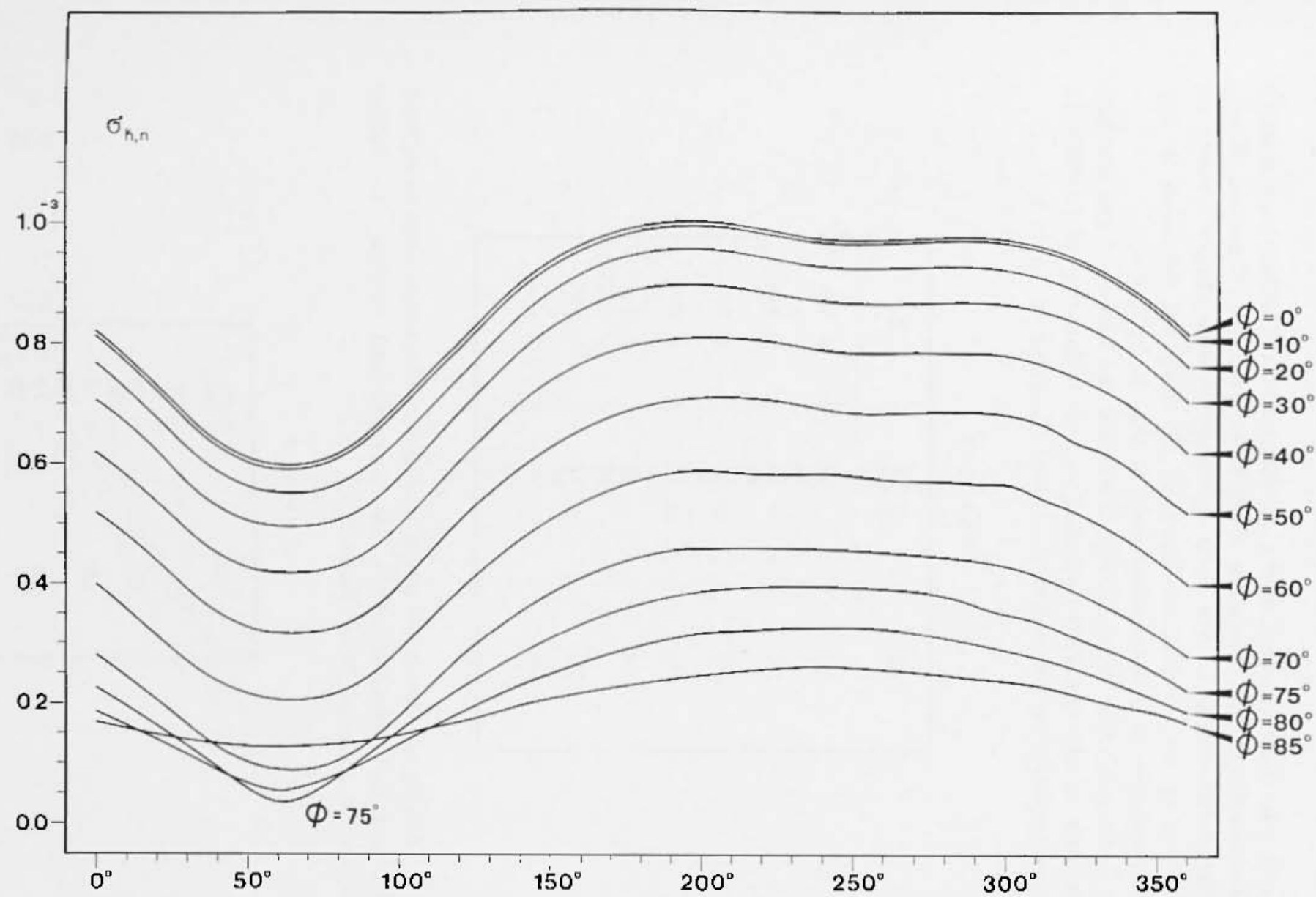

Fig. 2. - Representation of the values of the stanclarr deviation $\sigma_{k, m, n}$ corresponding to $\omega_{k}= \pm 0^{\prime \prime} .0012$, with the positive sign referring to motion of the $\Lambda$ merican plate and negative sign to motion of the Eurasian plate. 
sign referring to motion of the American block (Gaithersburg station) and the minus sign to motion of the Eurasian block (Mizusawa, Kitab, Carloforte stations). For each $\omega_{k}$ value we thus obtain a curve representing an absolute minimum of the standard deviation in correspondence to a determined pair of $\Phi_{m}, L_{n}$ values.

On the other hand, in Fig. 3 we find the curves of the absolute minima of the standarl deviation $\sigma_{k, m}$ as a function of latiturle $L_{n}$ corresponding to the values of $\omega_{k}$ and $\Phi_{m}$ given in Table 2.

Ta b I c 2

\begin{tabular}{|c|c|c|}
\hline Code & $\begin{array}{c} \pm \omega_{k} \\
\left(0^{\prime \prime} .001\right)\end{array}$ & $\Phi_{k}$ \\
\hline$(1)$ & \pm 12 & $+75^{\circ}$ \\
$(2)$ & \pm 14 & $+80^{\circ}$ \\
$(3)$ & \pm 16 & $+80^{\circ}$ \\
$(4)$ & \pm 16 & $+80^{\circ}$ \\
$(5)$ & \pm 15 & $+85^{\circ}$ \\
$(6)$ & \pm 12 & $+85^{\circ}$ \\
$(7)$ & $\therefore 12$ & $+85^{\circ}$ \\
\hline
\end{tabular}

Analogous eurves are given in Fig. $t$. The latter were calculaterl keeping the parameter $\Phi_{k}=82^{\circ}$ constant and varying the values of $\omega_{k}$, as appears from Table 3 .

Table 3

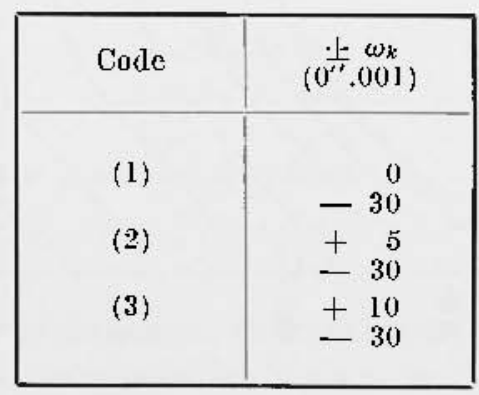




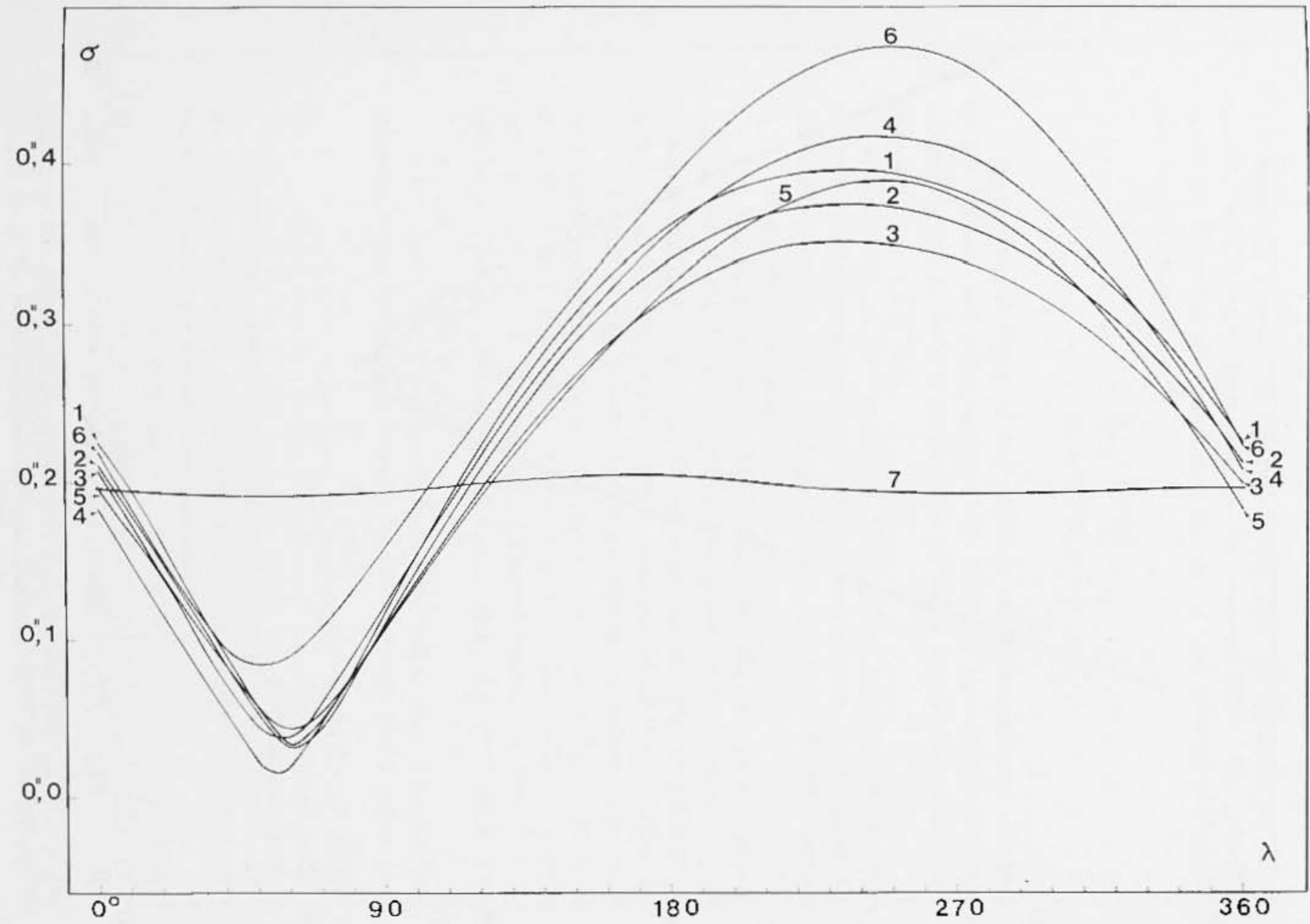

Firs. 3. - Diagram of the curves of the absolute minima of the standard deviation $\sigma_{h, s}$ is a function of latitude $L_{n}$ corresponding to the values of $\omega_{k}$ and $\phi_{m}$ given in Table 2 . 


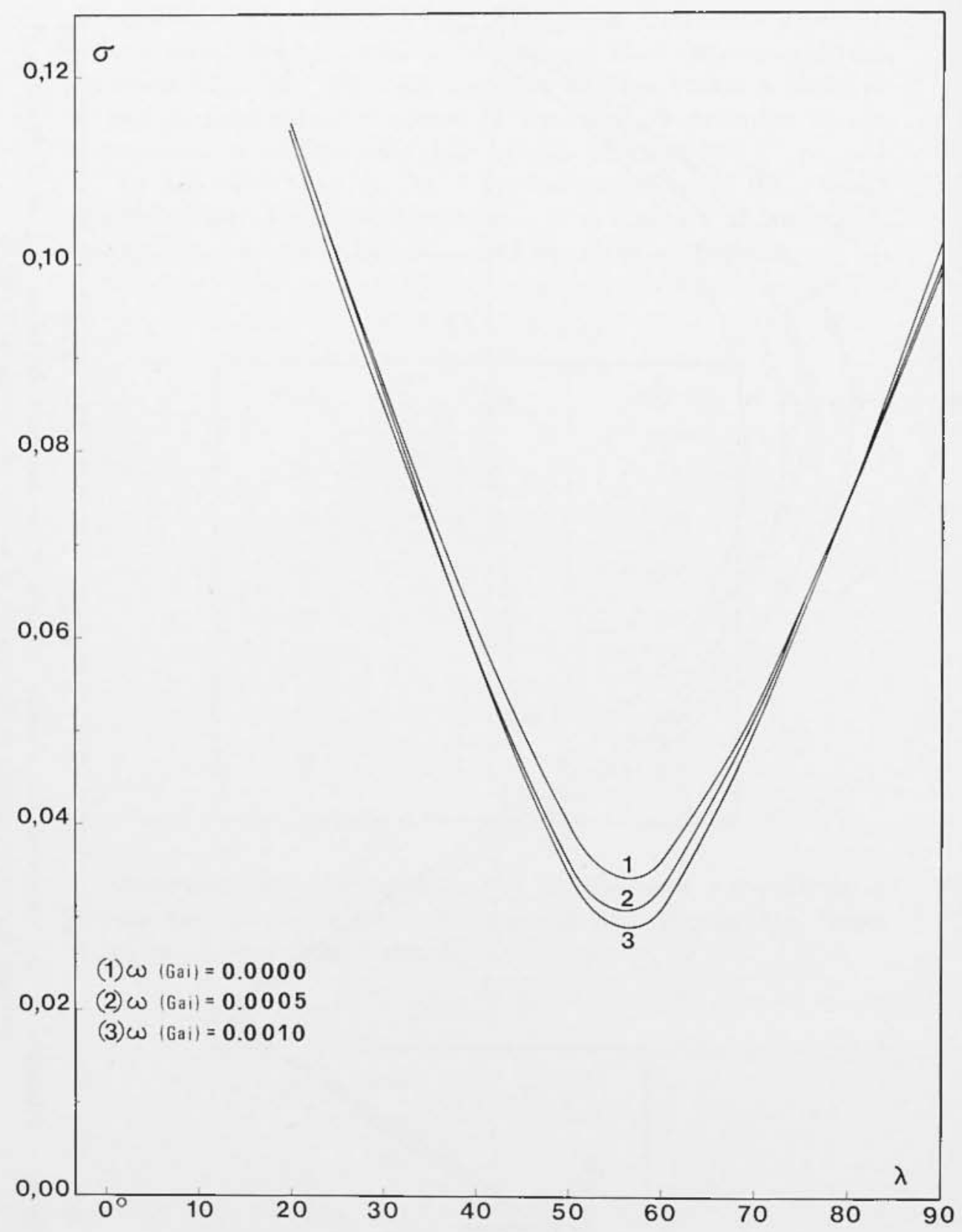

Fig. 4. - Jiagram of the eurves of standard deviation ealculated by kecping the parameter $\Phi_{k}=82^{\circ}$ constant and varying the values of $\omega_{k}$ as appears from Table 3 . 
From the wverige of the values $\Phi_{m}$ and $L_{n}$ obtained by minimixing the standard deviations in the various eases, the following values for the rotation center coordinates of the American-Eurasian plate were obtained:

$$
\begin{aligned}
& \Phi_{i}=82^{\circ} \mathrm{N} \\
& L_{k i}=57^{\circ} \mathrm{W}
\end{aligned}
$$

The averagel value of the rotation center coordinates obtained by Le Pichon and other authors by utilizing sprending rates and azimuth of the transform finlts given in Table 1 is, on the other launl, $\Phi=62^{\circ} \mathrm{N}, L=132 \circ \mathrm{E}$.

Comparison of the values of these latier coordinates to those we calculated slows that the two rotation centers are situatel approximately on the same meridian but on opposite sides with respect to the Earth rotation pole.

The values we found for the coorlinates $\Phi_{k}$ and $L_{k}$ are, in any case, includel within the ellipse of error given by Le Pichon ( ${ }^{2}$ ). This rather comforting result once again demonstrates the possibilities of astronomical data in studies on the secular motion of the Earth's crust.

In Fig. 5 we finul rejresented in a diagram the values of the stantlart tleviations $\sigma_{k}$ corresponding to the values $\Phi_{k}=820 \mathrm{~N}$ and $L_{k}=57^{\circ} \mathrm{W}$ and calculated by keeping fixed the value of angular velocity $\omega_{k}^{(2)}=+0^{\prime \prime} .0012$ of the American plate and changing the value $\omega_{i}^{(1)}$ (hivving a minus sign) of the angular velocity of the stations of the Eurasian plate.

From the curve interpolited from lig. 5 it is seen that the most, probable value for angular velocity of the Eurasian plate seems to be

$$
\omega_{i}^{(1)}=-0^{\prime \prime} .00205 / \text { year. }
$$

Successively using this value and varying the valne of $\mathrm{s}^{(2)}$, the minimum values of standard deviations relative to the various values of $\omega_{i}{ }^{(2)}$ introduced were determined.

In Fig. 6 the trend of the values of $\omega_{k}^{(2)}$ are represented. The curve presents a minimum in correspondence to the value $\omega_{i:}^{(2)}=+0^{\prime \prime}, 00125$. This value can be considered as being the most probable for the rotation speet of the U.S. American plate.

It is most interesting to observe that the most probable values of the angular velocities 


$$
\begin{aligned}
& \left(_{1} k^{(1)}=-0^{\prime \prime} .00295\right. \text { (Eurasian plate) } \\
& \omega_{k^{(2)}}=+0^{\prime \prime} .00125 \text { (American plate) }
\end{aligned}
$$

are in excellent agreement witl those obtained by an entirely independent way $\left.{ }^{(}\right)$and reported in the introduction of this paper.

The optimization method used in this paper is efficacious in the liypotlesis that the number of residuals $\Delta \varphi_{t}$ is greater than 1 . This las allowed the determination, as we have seen, of the most prob-

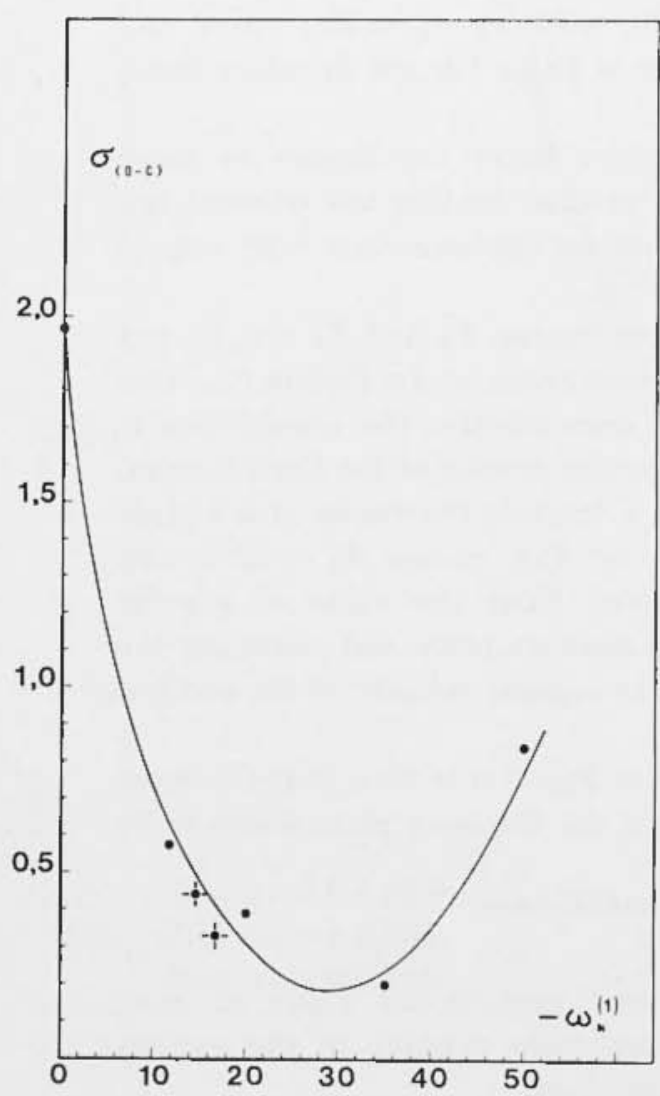

Fig. 5. - Diagram of the values of the standard deviation corresponding to the values $\Phi_{k}=82^{\circ} \mathrm{N}$ and $L_{k}=57^{\circ} \mathrm{WW}$ and ealeulated by leeping fixed the value of angular velocity of the American plate and changing the valuc of the Eurasian plate.

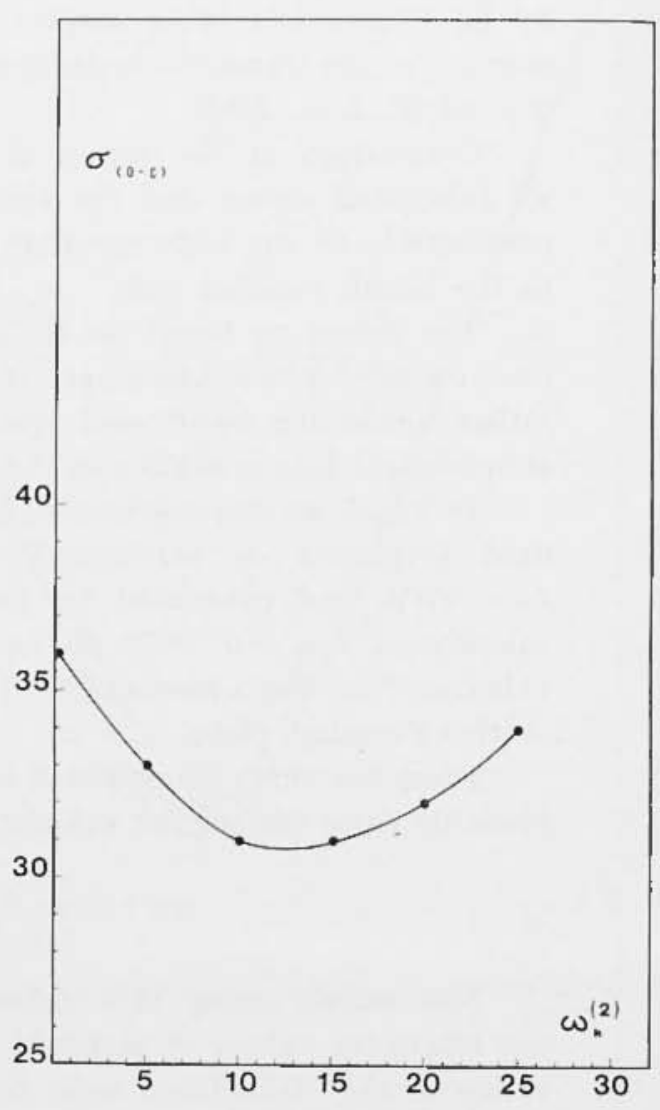

Fig. 6. - Representation of the trend of the values of $\omega_{k}\left({ }^{2}\right)$. The turve presents a minimum in corrispondence to the value $\omega_{k}\left({ }^{2}\right) \cdots+0^{\prime \prime} .00125$. 
able values of rotation center coordinates and of angular velocities (13. relative to the two American and Eurasian blocks.

In the case of the NE Pacific plate, we have only one value of the quantities $\Delta \psi_{i}$, corresponding to the Ukiall station (U.S.A.). In this circumstance it is thus completely impossible to obtain minima for the stantarl errors $\sigma$. However, it is possible even in this case to carry out an analysis of purely qualitative interest by determining the range of variability of the parameters $\Phi, L$ and $\omega$ which annul the resiciuals:

$$
\Delta \varphi=\left(b_{\mathrm{obs}}-b_{\mathrm{cal}}\right)=0
$$

In Fig. 7 , in bolid-faced type, the areas of variability of the parameters $\Phi, L$ and $\omega$ are represented, for which the previous condition
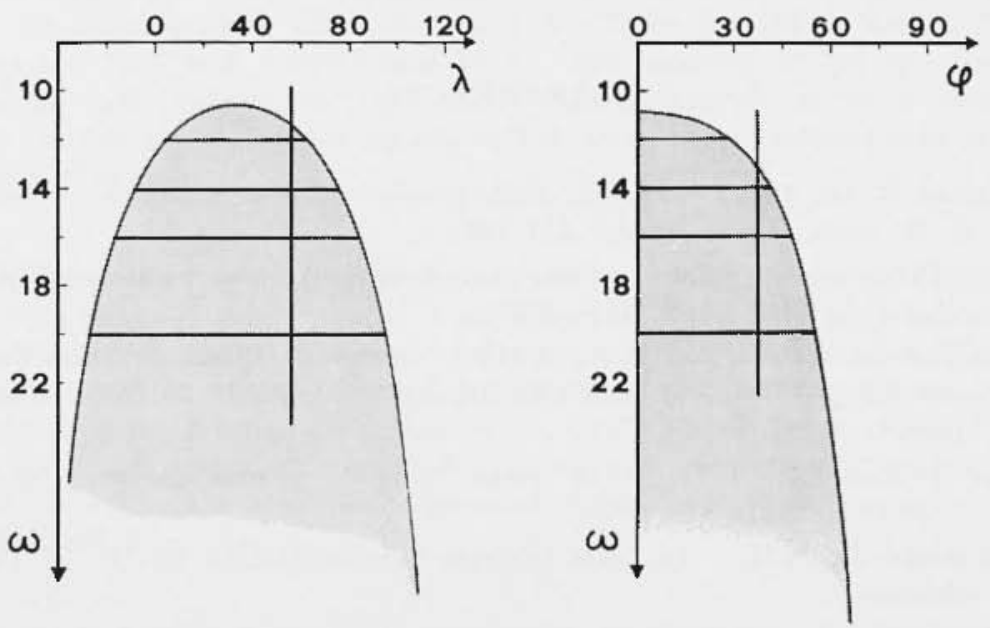

Fig. 7. - Representation of the arens of variability the parameters $\phi$, $I$, plate, ani of corresponding to the motion of the America-Pacific.

is actually verified. We consider it most significant that also in this case the values of the rotation center coordinates of the American-

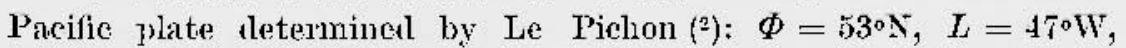
clearly indieated in the same Fir. $\tau$, fall witlin the areas of variability which, in a sense, represent the optimal areas of the values of the parameters $\phi$ and $L$. 


\section{Coxclusions}

To isomelusle:

a) using a procedure completely independent of the one used by $A . \Lambda .\left({ }^{6}\right)$, the most probable values of the coordinates and velocity of rotation of the American-Inusian plate were determined;

b) these values are in full agreement with those previously determined by A.A. $\left(^{6}\right)$ and are on the same oriler as those calculated with geopliysical and geologieal mensurements;

c) this confirms the possibility of using astronomical (latitute and longitude) observation data in the study of the secular motion of the Earth's crust.

\section{REFERENCES}

(1) Crase C. G., 1972. - The N. Plate problem of plate tectonics. "Geoph. J. R. Astr. Soe.", 29, pr. 117.122.

(2) Lu PICrox X., 1968. - Sea-Floor Spreading and continental drift. "J.G.R.", 73, 12, pp. 3661-3697.

(3) Le Picion X. and Fox P. J., 1971a. - Marginal Offsets, Fracture Zones, and Early Opening of the North Allantic. "J.G.R.", 76, 26, pp. 62946308.

(4) Le Picion X., 197l. - In press (private communication by Dr. J. Franchetcau).

(5) Mosgan J., 1971. - In mress (private communication by Dr. J. Franchetcau).

(6) Provjerio E. and Quesada V., 1972. - Analysis of secular polar molion and contineutal drift. In press. "Bull. Geod.". 